\section{Post-traumatic Lung Herniation through Chest Wall}

\section{Shegu Gilbert*, Devender Singh, Sivakumar MK}

Department of Cardiovascular and Thoracic Surgery, Kovai Medical Center and Hospital, Avinashi road, Coimbatore 641-014, Tamil Nadu, India

\begin{abstract}
Traumatic lung herniation through the chest wall is a rare clinical entity. Trauma may cause displacement, distortion and deficiency to the tissues of the chest wall which aids lung herniation. Here, we present a 68 year old gentleman who has sustained blunt injury to the left chest due to fall from a height after alcohol intake. He was treated with analgesics for musculoskeletal pain and then he was treated with antiplatelet for suspected angina. CT thorax shows a herniating left lower lobe that results from a defect in the sixth intercostal space and dislocation of the rib at the costochondral junction. Surgical repair for the defect was performed successfully and the patient was discharged home on the 6th post-operative day. There was no evidence of recurrent hernia at his 3-month follow-up visit.
\end{abstract}

Keywords: Lung hernia; Trauma; Hernia/surgery; Lung diseases/ etiology

\section{Introduction}

Herniation of lung is seen uncommon clinically. Lung hernia is defined as the protrusion of lung through one of its bounding structures [1]. We report a case of lung herniation following fall from a height after alcohol intoxication. He was misdiagnosed as angina and treated with anti-platelets

\section{Case Report}

A 63 years old gentleman had fall from a height after a bout of alcohol intake and intoxication. Following this, first he was treated at a local hospital with analgesics and then for angina with anti-platelets. $\mathrm{He}$ was observed under emergency for one day after the incident. $\mathrm{He}$ has pain over the left lower rib cage on deep breathing and coughing. On chest examination bluish discoloration (bruising) was seen all over the site ( $6^{\text {th }}$ and $7^{\text {th }}$ ribs anteriorly). There was no laceration in the skin, the swelling was compressible and wide gap could be felt in $6^{\text {th }}$ inter costal space. On examination, the vital signs are noted as pulse $=98 /$ min, blood pressure $=110 / 60 \mathrm{mmHg}$. Respiratory rate $=34 / \mathrm{min}$, oxygen saturation $=92 \%$, afebrile, On local examination an ill defined, nontender, soft swelling $12 \times 5 \mathrm{~cm}$ was present in the sixth ICS with positive cough impulse. Hemogram was normal.

Chest X-ray postero-anterior view showed haziness over left lower zone (Figure 1). HRCT (high resolution computed tomography) thorax showed herniation of lower lobe through sixth ICS (intercostal space) and dislocation of the rib at costochondral junction (Figure 2). The patient was requested to take bed rest, oxygen, brochodilators, cough suppressant and analgesics.

The patient was advised surgical repair and informed consent was taken. He was taken up for surgical repair and incision was given for antero lateral thorocotomy in the $6^{\text {th }}$ ICS. The entire length of parietal pleura and inter costal muscles were found to be lacerated from costal attachments to mid axillary line. There was dislocation of the $7^{\text {th }}$ costal cartilage along with lower rib cage. The defect is measured to be 16 $\mathrm{cm}$. There was no rib fracture or lung contusion. The diaphragmatic attachment to the costal margins was torn. The herniated left lower lobe was first reduced into the pleural cavity. Secondly, we fixed the $7^{\text {th }}$ costal margin to sternum using number 2 sternal wire. Then the diaphragm tear was repaired using $3 / 0$ prolene with interrupted sutures. Finally, the $6^{\text {th }}$ and $7^{\text {th }}$ ribs were approximated using interrupted pericostal $1 / 0$ prolene sutures (Figure 3). Also, the routine three layer closure of chest wall was done.

The patient was shifted to ICU and extubated after $6 \mathrm{~h}$. Postoperative period was uneventful and he was discharged on $6^{\text {th }}$ day.

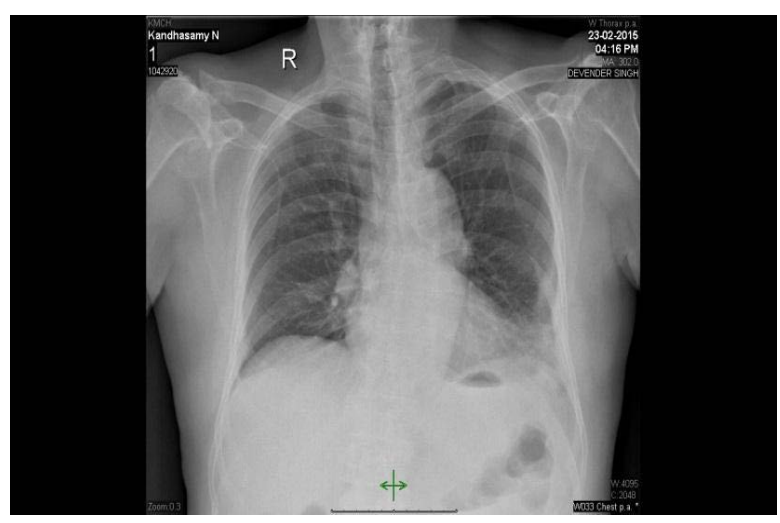

Figure 1: Chest X-ray.

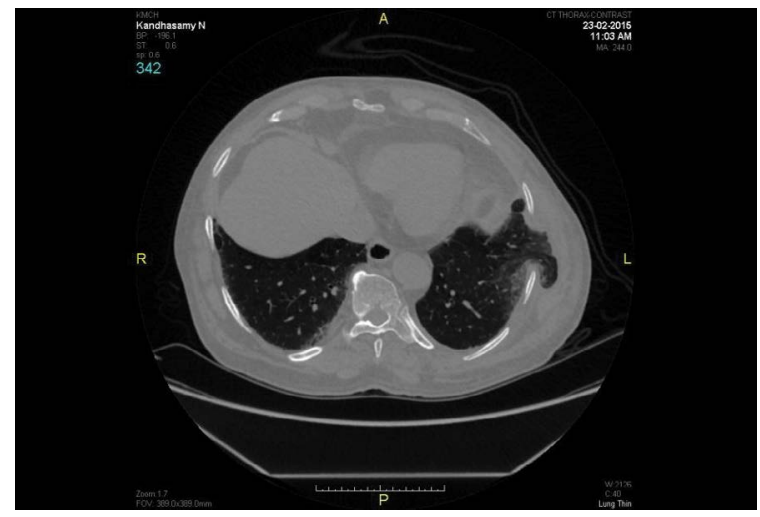

Figure 2: HRCT lung hernia.

${ }^{*}$ Corresponding author: Shegu Gilbert, Department of Cardiovascular and Thoracic Surgery, Kovai Medical Center and Hospital, Avinashi road, Coimbatore 641-014, Tamil Nadu, India, E-mail: shegugilbert@yahoo.co.in

Received April 14, 2015; Accepted July 02, 2015; Published July 07, 2015

Citation: Gilbert S, Singh D, Sivakumar MK (2015) Post-traumatic Lung Herniation through Chest Wall. J Pulm Respir Med 5: 270. doi:10.4172/2161-105X.1000270

Copyright: $\odot 2015$ Gilbert S, et al. This is an open-access article distributed under the terms of the Creative Commons Attribution License, which permits unrestricted use, distribution, and reproduction in any medium, provided the original author and source are credited. 


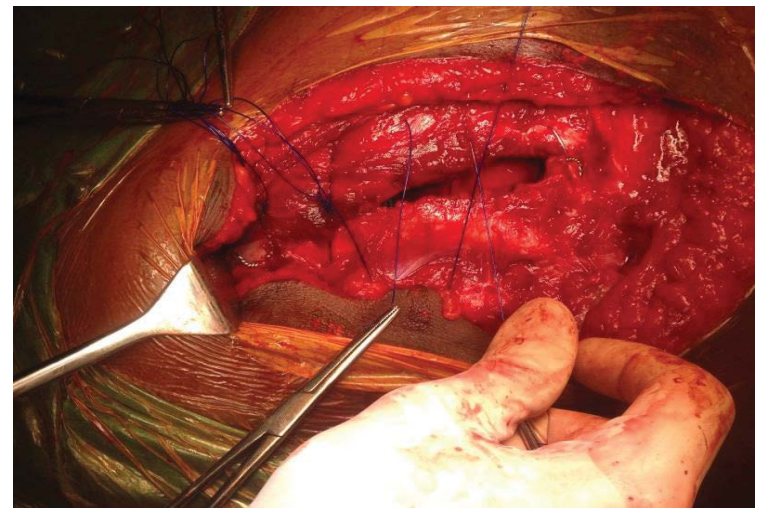

Figure 3: Operative image.

\section{Discussion}

Lung hernia is classified according to the anatomic location such as cervical, thoracic, diaphragmatic or mediastina [2]. According to the etiological classification it can be congenital or acquired. Acquired hernias are further classified as traumatic, consecutive, and spontaneous or pathological [3]. Traumatic is due to weakness of chest wall developed as a result of penetrating chest wound, surgical intervention, fractured rib etc.

In our case it is possibly due to the dislocation of costochondral junction from sternum (anteriorly) because there is lack of external intercostal muscle in this case particularly. Secondly, there could be a possible increase in intrathoracic pressure due to violent cough due to COPD.
Diagnosis is generally made in the presence of soft crepitant protrusion which is reducible on quiet respiration and again bulges forward on coughing or valsalva's maneuver. The defect in chest wall was palpable. CT thorax confirmed the diagnosis.

The following condition must be considered for differential diagnosis such as subcutaneous emphysema, cold abscess, emphysema necessitans and lipoma/angioma.

Lung hernias require surgical management if it causes constant pain, recurrent infection, respiratory distress or progressive increase in size. In our case, it was pain and respiratory distress.

A variety of surgical procedures have been described, most of which includes using both autologous tissue such as muscle or fascia layers and synthetic mesh layers [4,5]. Wien's et al. has described use of laminar hooks as used in spinal injuries [6].

\section{References}

1. Montgomery JG, Lutz H (1925) HERNIA OF THE LUNG. Ann Surg 82: 220231 .

2. Donato AT, Hipona FA, Navani S (1973) Spontaneous lung hernia. Chest 64 254-256.

3. Prasad R, Mukerji PK, Gupta H (1990) Herniation of the lung. Indian J Chest Dis Allied Sci 32: 129-132.

4. Weissberg D, Refaely Y (2002) Hernia of the lung. Ann Thorac Surg 74: 19631966.

5. Szentkereszty Z, Boros M, Sápy P, Kiss SS (2006) Surgical treatment of intercostal hernia with implantation of polypropylene mesh. Hernia 10: 354-356.

6. Wiens S, Hunt I, Mahood J, Valji A, Stewart K, et al. (2009) Novel fixation technique for the surgical repair of lung hernias. Ann Thorac Surg 88: 10341035. 